\title{
Core circadian clock genes Per1 and Per2 regulate the rhythm in photoreceptor outer segment phagocytosis
}

\author{
Nemanja Milićević $\mathbf{c}^{1,2}$ (D) | Ouafa Ait-Hmyed Hakkari ${ }^{2}$ ｜ Udita Bagchi ${ }^{1,2}$ (D) | \\ Cristina Sandu $^{2}$ (D) | Aldo Jongejan ${ }^{3}$ (i) | Perry D. Moerland ${ }^{3}$ (i) | \\ Jacoline B. ten Brink $^{1}$ ｜ David Hicks ${ }^{2}$ | Arthur A. Bergen ${ }^{1,4,5}$ (D) | \\ Marie-Paule Felder-Schmittbuhl ${ }^{2}$ \\ ${ }^{1}$ Department of Clinical Genetics, Amsterdam UMC, University of Amsterdam, Amsterdam, the Netherlands \\ ${ }^{2}$ Centre National de la Recherche Scientifique, Institut des Neurosciences Cellulaires et Intégratives, Université de Strasbourg, Strasbourg, France \\ ${ }^{3}$ Bioinformatics Laboratory, Department of Epidemiology and Data Science, Amsterdam Public Health Research Institute, Amsterdam UMC, Amsterdam, \\ the Netherlands \\ ${ }^{4}$ Department of Ophthalmology, Amsterdam UMC, University of Amsterdam, Amsterdam, the Netherlands \\ ${ }^{5}$ Netherlands Institute for Neuroscience (NIN-KNAW), Amsterdam, the Netherlands
}

\section{Correspondence}

Arthur A. Bergen, Department of Clinical

Genetics, Amsterdam UMC, University

of Amsterdam, Meibergdreef 9, 1105

AZ, Amsterdam, North Holland, the

Netherlands.

Email: aabergen@amsterdamumc.nl

Marie-Paule Felder-Schmittbuhl, Centre

National de la Recherche Scientifique,

Université de Strasbourg, Institut des

Neurosciences Cellulaires et Intégratives,

8 Allée du Général Rouvillois, F-67000

Strasbourg, France.

Email: feldermp@inci-cnrs.unistra.fr

\section{Present address}

Nemanja Milićević, Faculty of Medicine and Health Technology, Tampere

University, Tampere, Finland

\begin{abstract}
Retinal photoreceptors undergo daily renewal of their distal outer segments, a process indispensable for maintaining retinal health. Photoreceptor outer segment (POS) phagocytosis occurs as a daily peak, roughly about 1 hour after light onset. However, the underlying cellular and molecular mechanisms which initiate this process are still unknown. Here we show that, under constant darkness, mice deficient for core circadian clock genes (Perl and Per2) lack a daily peak in POS phagocytosis. By qPCR analysis, we found that core clock genes were rhythmic over 24 hours in both WT and Perl, Per 2 double mutant whole retinas. More precise transcriptomics analysis of laser capture microdissected WT photoreceptors revealed no differentially expressed genes between time points preceding and during the peak of POS phagocytosis. In contrast, we found that microdissected WT retinal pigment epithelium (RPE) had a number of genes that were differentially expressed at the peak phagocytic time point compared to adjacent ones. We also found a number of differentially expressed genes in Perl, Per 2 double mutant RPE compared to WT ones at the peak phagocytic time
\end{abstract}

\footnotetext{
Abbreviations: Bmal1, brain and muscle ARNT-like 1; BP, biological process; CPM, counts per million; Cry, cryptochrome; DD, constant darkness; DEGs, differentially expressed genes; FDR, false discovery rate; Hprt, hypoxanthine phosphoribosyltransferase; KEGG, Kyoto encyclopedia of genes and genomes; LCM, laser capture microdissection; LD, light-dark cycle; MF, molecular function; Per, period; POS, photoreceptor outer segment; Ror, RAR-related orphan receptor; ROS, rod outer segment; RPE, retinal pigment epithelium; SCN, suprachiasmatic nucleus; Tbp, TATA-Box-binding Protein; WP, WikiPathways; WT, wild type; ZT, Zeitgeber time.
}

Nemanja Milićević, Ouafa Ait-Hmyed Hakkari are equal first author contribution.

Arthur A. Bergen, and Marie-Paule Felder-Schmittbuhl are equal last author contribution.

This is an open access article under the terms of the Creative Commons Attribution-NonCommercial License, which permits use, distribution and reproduction in any medium, provided the original work is properly cited and is not used for commercial purposes.

() 2021 The Authors. The FASEB Journal published by Wiley Periodicals LLC on behalf of Federation of American Societies for Experimental Biology 
Funding information

EC I Erasmus+ Neurotime; Nelly Reef Fund (Nelly Reef Foundation); Stichting voor Ooglijders; Stichting tot Verbetering van het Lot der Blinden (Het Lot); Rotterdamse Stichting Blindenbelangen, Grant/Award Number: HV/AB/B20170031; Retina France point. Finally, based on STRING analysis, we found a group of interacting genes that potentially drive POS phagocytosis in the RPE. This potential pathway consists of genes such as: Pacsin1, Syp, Camk2b, and Camk2d among others. Our findings indicate that Per 1 and Per 2 are necessary clock components for driving POS phagocytosis and suggest that this process is transcriptionally driven by the RPE.

\section{K E Y W O R D S}

circadian rhythm, clock gene, phagocytosis, photoreceptor, photoreceptor outer segment, retinal pigment epithelium

\section{\begin{tabular}{l|l}
1 & INTRODUCTION
\end{tabular}}

Light/dark transitions are one of the hallmarks of life on Earth. Living organisms adapt their behavior and physiology according to cyclic changes in environmental conditions. In mammals, these rhythmic adjustments in molecular and cellular physiology are enabled through a hierarchical network of oscillators, encompassing a "central clock" located in the suprachiasmatic nucleus $(\mathrm{SCN})$ in the brain and peripheral oscillators. ${ }^{1}$ The core molecular components generating these oscillations are comprised of interlocking transcriptionaltranslational feedback loops involving "clock" transcription factors such as PER1-2, CLOCK, BMAL1, CRY1-2, REVERBs, and ROrs. ${ }^{2}$ These factors drive rhythmic expression of "clock-controlled genes" thereby enabling rhythmic adaptations in physiology.

The retina stands out as a peripheral oscillator as it lies in direct contact with the main environmental synchronizing stimulus-light. ${ }^{3}$ This light-sensitive organ is composed of multiple layers of cells, all of which were shown to oscillate in a layer-specific manner and are strongly coupled. ${ }^{4}$ Numerous aspects of retinal physiology and functions were shown to be rhythmic ${ }^{5}$ such as melatonin release, ${ }^{6,7}$ rod-cone coupling, ${ }^{8,9}$ visual sensitivity, ${ }^{10,11}$ and photoreceptor disc shedding. ${ }^{12}$ Of all retinal cells, circadian oscillations in photoreceptors have been most extensively studied (reviewed 13).

Retinal photoreceptors are specialized, light-sensitive neuronal cells. They are metabolically highly active cells in which homeostasis is tightly controlled. They consist of a cell body, a specialized synapse, inner, and outer segments. Together with the adjacent retinal pigment epithelium (RPE), the POS contains the molecular machinery that sustains phototransduction. Excessive light exposure can damage these cells. A mechanism that prevents the accumulation of photo-oxidative compounds is rapid POS renewal. ${ }^{14}$ This turnover involves several critical steps. At the proximal POS end, these steps include synthesis and intracellular transport of structural and functional proteins. At the distal end, POS fragments are shed and subsequently phagocytosed by the RPE. Impairment of phagocytosis was previously implicated in photoreceptor degeneration in both animal models ${ }^{15}$ and humans. ${ }^{16}$ Despite many studies devoted to the subject, the molecular mechanisms that control POS phagocytosis remain elusive. ${ }^{5,17,18}$ Phagocytosis of POS was shown to be highly cyclic, taking place in rods as a daily peak occurring about 1 hour after light is turned on in both nocturnal and diurnal mammals. ${ }^{12,19,20}$ This peak is maintained under constant darkness, implicating circadian control. However, little is known about the transcriptional events that occur prior and during the peak of POS phagocytosis.

In the present study, we tested the hypothesis that Perl and Per2 are necessary clock components for initiating the phagocytosis of rod outer segments in mice. We investigated the transcriptional changes that occur in the RPE and photoreceptors prior and during the peak in POS phagocytosis. Finally, we proposed a potential pathway for initiating POS phagocytosis based on our transcriptomics data obtained from multiple time points, purest possible microdissected sample material, and phagocytically arrhythmic Perl, Per2 mouse double knockout model.

\section{2 | METHODS}

\section{1 | Animals}

Experiments were conducted using homozygote double mutant mice carrying the loss-of-function mutation of $\mathrm{mPer} 1$ gene $\left(\mathrm{Perl}^{-/-} ; 21\right)$ and mutation of the $\mathrm{mPer} 2$ gene $\left(\mathrm{Per}^{\mathrm{Brdml}}, 22\right.$; hereafter defined as $\mathrm{Per}^{-/} \mathrm{Per} 2^{\mathrm{Brdml}}$ or KO). Intercrosses between heterozygous (C57BL/6/J x $129 \mathrm{SvEvBrd)} \mathrm{F1} \mathrm{offspring}$ gave rise to $\mathrm{F} 2$ homozygous mutants. Mutant and wild-type (WT) animals on this mixed background were used in this study, maintained as described in. ${ }^{23}$ Mice were maintained in our animal facilities (Chronobiotron, UMS3415, Strasbourg, France) on a 12 hours light/12 hours dark (LD) cycle (300 lux during the light phase), with an ambient temperature of $22 \pm 1^{\circ} \mathrm{C}$. The animals were given free access to food and water. In all experiments, control and mutant mice were agematched. Only male mice were used for the RNAseq study, 
but both males and females were used for qPCR experiments and phagocytosis analysis. All experimental procedures were performed in accordance with the Association for Research in Vision and Ophthalmology Statement on Use of Animals in Ophthalmic and Vision Research, as well as with the European Union Directive (2010/63/EU). Age-matched WT and $P e r 1^{-/-} P e r 2^{B r d m l}$ mice (6 weeks old) were sacrificed in constant darkness (dark/dark, DD) at time points (expressed in circadian time (CT); CT0 - time when lights were on during LD conditions, CT12-lights off in LD conditions) specific to each experiment. Sacrifice was performed under complete darkness by night-vision goggles ATN NVG-7 (American Technologies Network Corp., San Francisco, CA, USA) and eye sampling was performed under dim red light $(<5$ lux $)$. Animals were anesthetized by $\mathrm{CO}_{2}$ inhalation and subsequently killed by cervical dislocation.

\subsection{Genotyping}

Mice were genotyped by PCR amplification of tail DNA with four sets of primers specific either for the genomic regions that were deleted in mutants but present in WT ( $5^{\prime}-\mathrm{GT}$ CTTGGTCTCATTCTAGGACACC and 5'-AACATGAGAG CTTCCAGTCCTCTC for Perl gene; 5'-AGTAGGTCGTC TTCTTTATGCCCC and 5'-CTCTGCTTTCAACTCCTGT GTCTG for Per2 gene) or for the recombinant alleles present in mutants only (5'-ACAAACTCACAGAGCCCATCC and 5'-ACTTCCATTTGTCACGTCCTGCAC for $\mathrm{Perl}^{-/-}$, $5^{\prime}$-TTTGTTCTGTGAGCTCCTGAACGC and 5'-ACTTCC ATTTGTCACGTCCTGCAC for $P e r 2^{\text {Brdml }}$ ).

\section{3 | Immunohistochemistry}

Eye globes were immersion-fixed in $4 \%$ paraformaldehyde in phosphate-buffered saline (PBS) overnight at $4^{\circ} \mathrm{C}$. Eyeballs were rinsed in PBS, cut into two hemispheres, and cryoprotected upon transfer to an ascending series of sucrose solutions $(10 \%, 20 \%$, and 30\% each for 1 hour) and then embedded (Tissue-Tek OCT compound; Thermo-Shandon, Pittsburg, PA, USA). Cryostat sections (10 $\mu \mathrm{m}$ thick) were permeabilized for 5 minutes with $0.1 \%$ Triton X-100 and saturated with PBS containing $0.1 \%$ bovine serum albumin, $0.1 \%$ Tween-20, and $0.1 \%$ sodium azide for 30 minutes. Sections were incubated overnight at $4^{\circ} \mathrm{C}$ with monoclonal anti-rhodopsin antibody Rho-4D $2 .{ }^{24}$ Secondary antibody incubation was performed at room temperature for 2 hours with Alexa 488 anti-mouse IgG-conjugated antibodies (Molecular Probes Inc, Eugene, OR, USA). Cell nuclei were stained with DAPI (Molecular Probes). Slides were washed thoroughly, mounted in PBS/glycerol (1:1), and observed by an epifluorescence microscope (Nikon Optiphot 2). The number of phagosomes was quantified, as described previously by us. ${ }^{19}$ Transverse sections were obtained from the central retina, covering the whole width of the retina from one periphery to the other. Taking the POS/RPE interface as a baseline, any immunopositive inclusion exceeding $1 \mu \mathrm{m}$ lying within the RPE subcellular space was scored as a phagosome. Phagosomes were counted by aligning a $150 \mu \mathrm{m} \times 150 \mu \mathrm{m}$ grid parallel with the RPE layer and displacing it dorsally and ventrally (a total of 20 grids were counted per section) with respect to the optic nerve, along the POS/RPE interface. Phagosomes were counted on 12 sections per eye ( 1 eye per animal) and averages of these values represent 1 data point in our quantification. Thus, the data presented are the means of the numbers of phagosomes per complete retina section. Our strategy for quantifying POS phagocytosis is one of a number of generally accepted methods and is employed by a number of groups who study mechanisms of RPE-mediated POS phagocytosis. ${ }^{17,18,25-30}$ The representative images (Figure 1B) are blurry due to fluorescence emitted from the specimen outside the focal plane. ${ }^{31}$ They contain oversaturation of the Rho-4D2 stained OS layer to visualize the relatively faint Rho-4D2 stained phagosomes in the RPE cell layer.

\section{$2.4 \quad$ RT-qPCR gene expression analysis}

Retinas were sampled immediately after sacrifice. A small incision was performed on the cornea with a sterile blade, lens and vitreous were discarded, and the retina was directly collected with sterile forceps and immediately frozen in liquid nitrogen and stored at $-80^{\circ} \mathrm{C}$.

Retinas were homogenized in the RNAble (Eurobio Scientific, France) solution by a 23 -gauge sterile needle and $1 \mathrm{~mL}$ syringe and mRNA extracted according to the manufacturer's recommendations. Resuspended RNA was treated with DNAse I ( $0.1 \mathrm{U} / \mu \mathrm{l}, 30$ minutes, $37^{\circ} \mathrm{C}$-Fermentas) followed by phenol/chloroform/isoamyl alcohol extraction and sodium acetate/isopropanol precipitation. RNA concentration and purity were measured using NanoDrop ND-1000V 3.5 Spectrophotometer (NanoDrop Technologies, Wilmington, DE, USA; A260/A280 and A260/A230 values were between 1.8 and 2). RNA quality was evaluated with the Bioanalyzer 2100 (Agilent Technologies; RNA integrity (RIN) numbers were between 7.8 and 9).

Five hundred nanograms of total RNA were reverse transcribed by random primers and the "High Capacity RNAto-cDNA" kit (Applied Biosystems, Foster City, CA, USA) following the manufacturer's instructions. qPCR was performed using the 7300 Real-Time PCR System (Applied Biosystems) and the hydrolyzed probe-based TaqMan chemistry, with optimized Gene Expression Assays designed for specific mRNA amplification (Table 1). We used the TaqMan Universal PCR Master Mix with No AMPErase 


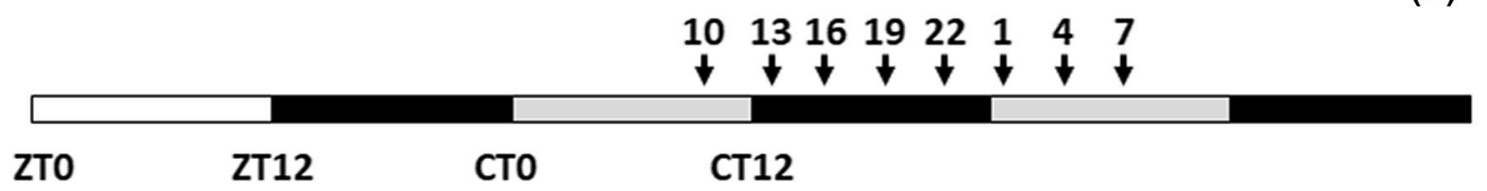

(B)

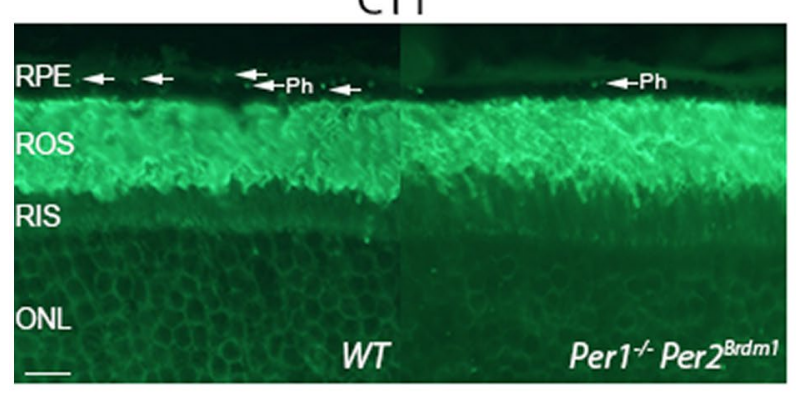

(C)

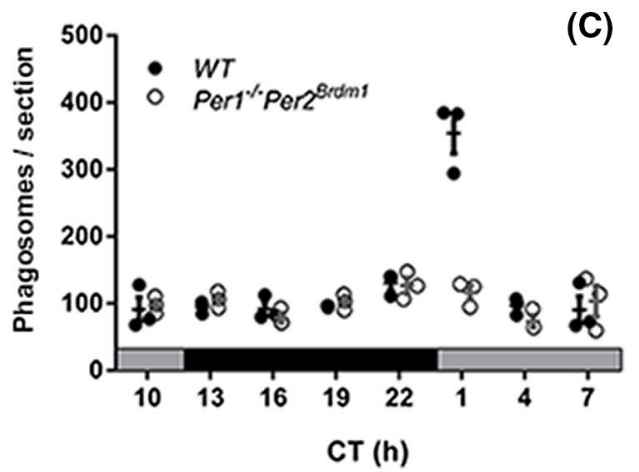

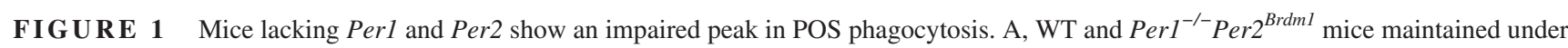
12 hours light (white bar)-dark (black bar) conditions were placed under constant darkness (DD, grey-black bars) and sacrificed at time points indicated by arrows. B, Representative image of Rho-4D2 stained phagosomes of WT and Per $^{-/}$Per2 $^{\text {Brdml }}$ retinas obtained at CT1 during the peak in phagocytosis in DD conditions. ONL, outer nuclear layer; Ph, phagosomes; RIS, rod inner segments; ROS, rod outer segments; RPE, retinal pigment epithelium. The scale bar is $10 \mu \mathrm{m}$. C, Quantification of phagosomes in WT and $\operatorname{Per}^{-/-}{ }_{\text {Per2 }}^{\text {Brdml }}$ retinas under DD showed that $\operatorname{Per}^{-1-}$ Per $2^{\text {Brdml }}$ mice had no detectable peak in ROS phagocytosis. $\mathrm{N}=3$ /genotype/time point. Graphs show mean $\pm \mathrm{SEM}$ and values from individual samples are shown as dots

\begin{tabular}{llllll} 
Gene & $\begin{array}{l}\text { TaqMan assay } \\
\text { reference }\end{array}$ & RefSeq & $\begin{array}{l}\text { Exon/exon } \\
\text { boundary }\end{array}$ & $\begin{array}{l}\text { Assay } \\
\text { location }\end{array}$ & $\begin{array}{l}\text { Amplicon } \\
\text { length (bp) }\end{array}$ \\
\hline Clock & Mm00455950_m1 & NM_007715.5 & $15-16$ & 1592 & 81 \\
\hline Bmal1 & Mm00500226_m1 & NM_007489.3 & $11-12$ & 1193 & 87 \\
\hline Per1 & Mm00501813_m1 & NM_011065.4 & $18-19$ & 2628 & 106 \\
\hline Per2 & Mm00478113_m1 & NM_011066.3 & $19-20$ & 3271 & 73 \\
\hline Per3 & Mm00478120_m1 & NM_011067.2 & $4-5$ & 984 & 73 \\
\hline Cry1 & Mm00514392_m1 & NM_007771.3 & $1-2$ & 740 & 64 \\
\hline Cry2 & Mm00546062_m1 & NM_009963.4 & $1-2$ & 254 & 70 \\
\hline Rev-Erb $\alpha$ & Mm00520708_m1 & NM_145434.3 & $1-2$ & 531 & 62 \\
\hline Rorb & Mm00524993_m1 & NM_146095 & $2-3$ & 201 & 74 \\
Tbp & Mm00446971_m1 & NM_013684.3 & $2-3$ & 305 & 93 \\
\hline Hprt & Mm01324427_m1 & NM_013556.2 & $5-6$ & 543 & 108 \\
\hline & & & & & \\
\hline
\end{tabular}

TABLE 1 List of primers used for the qPCR analysis of WT and $\operatorname{Perl}^{-/-}$Per2 $2^{\text {Brdml }}$ mouse whole retinas
UNG (Applied Biosystems) and $1 \mu \mathrm{L}$ of cDNA in a total volume of $20 \mu \mathrm{L}$. The PCR program was 10 minutes at $95^{\circ} \mathrm{C}$ and then 40 cycles of 15 seconds at $95^{\circ} \mathrm{C}$ and 1 minute at $60^{\circ} \mathrm{C}$. The fluorescence acquisition was performed at the end of the elongation step (7300 System Sequence Detection Software V 1.3.1-Applied Biosystems). Each PCR reaction was performed in duplicate. A dilution curve of the pool of all cDNA samples from one series was used to determine working dilution and to calculate the amplification efficiency for each assay (values were between 1.8 and 2 for all assays).
No-template control reactions were performed as negative controls for each assay. One 96-well plate corresponded to the analysis of one gene and one genotype. Data analysis was performed with qBase software (free v1.3.5) ) $^{32}$ and transcript levels were normalized using Hprt and Tbp that showed constant expression (Cosinor analysis of their relative expression levels as expressed by eff ${ }^{-\Delta \mathrm{Ct}} ; P=.676$ for $H$ prt in WT; $P=.992$ for Tbp in WT; $P=.219$ for Hprt in KO; $P=.347$ for $T b p$ in KO) in their mRNA during the 24-hours cycle (data not shown). We used the geometric means of the 
relative expression levels of Hprt and Tbp genes to normalize the data of all target genes. Within one experiment (one gene expression profile, one genotype), relative expression levels were calculated relative to the average expression of the dataset throughout the 6 time points, which was rescaled to one. In this configuration, the amplitudes determined by cosinor analysis represent the maximal deviation from the $100 \%$ mean and can potentially be compared between genotypes, as was previously performed by Hiragaki and colleagues. ${ }^{33}$

\section{5 | Laser capture microdissection}

Eye globes ( $\mathrm{n}=4$ animals/genotype/time point) were enucleated under dim red light $(<5$ lux $)$, embedded in OCT, snap-frozen and stored at $-80^{\circ} \mathrm{C}$ until use. Eyes were cryosectioned at $10 \mu \mathrm{m}$ thickness. Each eye provided 116-258 sections. All sections were dehydrated with ethanol and stained with cresyl violet staining (LCM Staining Kit, Ambion) and air-dried before microdissection with a laser microdissection system (LCM; PALM, Bernried, Germany). The RPE and photoreceptors were isolated with LCM (Figure S1). The number of eye sections used for LCM RPE and photoreceptor isolation between genotypes was similar with $183 \pm 10.18$ (mean \pm SD) slices used from WT eyes, whereas $201.3 \pm 8.91$ slices were used from double mutants $(P=.19$, Student's t test).

\subsection{RNA isolation for RNA sequencing}

Total RNA was isolated using an RNeasy Micro kit (Qiagen Benelux, Venlo, The Netherlands), quantified with a NanoDrop (Isogen Life Science BV, The Netherlands) and the quality was checked on a Bioanalyzer (Agilent Technologies, Amstelveen, The Netherlands). Sample RIN values for photoreceptors ranged from 7 to 9.8, except for three samples $(\mathrm{RIN}=3.2,4.1,4.1)$. For RPE samples, RIN values ranged from 5 to 9.5 .

\section{7 | Library preparation and RNA sequencing}

We used the KAPA mRNA HyperPrep kit (Illumina Platforms). For generating libraries, we used one batch of $20 \mathrm{ng}$ of total photoreceptor ( $\mathrm{n}=1 /$ genotype/time point) RNA and $30 \mathrm{ng}$ for the other three batches ( $\mathrm{n}=3$ /genotype/ time point) according to the manufacturer's protocol (Illumina Platforms). For generating libraries from RPE samples, we used 20 ng of RNA. In case of low RNA yield, two samples were pooled, resulting in three independent biological replicates per genotype and time point for library synthesis. RPE libraries were generated in three batches.

The presence of cDNA was confirmed using flash gels (cat No. 57032, Lonza, Rockland, ME, USA). Libraries were 50 bp single-end sequenced using the Illumina HiSeq 4000 platform.

\section{8 | Bioinformatics}

The photoreceptor and RPE RNA-seq data were analyzed separately, but with the same software versions and parameter settings unless indicated otherwise. Raw sequencing data were subjected to quality control using FastQC (v.0.11.15), Picard Tools, and dupRadar. ${ }^{34}$ All samples were of sufficient quality. Reads were trimmed for adapter sequences using Trimmomatic (v0.32). ${ }^{35}$ Trimmed reads were aligned to the mouse genome (Ensembl GRCm38.p6) using HISAT2 (v2.1.0). ${ }^{36}$ Gene level counts were obtained using HTSeq $(\mathrm{v} 0.11)^{37}$ with default parameters except - stranded $=$ reverse and the mouse GTF from Ensembl (release 93). Statistical analyses were performed using the edge $\mathrm{R}^{38}$ and limma $\mathrm{R}$ (v3.5.0)/Bioconductor (v3.7) packages. ${ }^{39}$ Genes with more than two counts in four or more samples (photoreceptors) or in three or more samples (RPE) were retained. Count data were transformed to $\log 2$-counts per million $(\log \mathrm{CPM})$, normalized by applying the trimmed mean of $M$-values method and precision weighted using voom. ${ }^{40}$ Pairwise differential expression between the conditions of interest was assessed using an empirical Bayes moderated t test within limma's linear model framework, including the precision weights estimated by voom. Both for WT and Per1 ${ }^{-/} \operatorname{Per}^{\text {Brdml }}$, a moderated $\mathrm{F}$ test was used to determine which genes are differentially expressed between time points. The resulting $p$-values were corrected for multiple testing using the Benjamini-Hochberg false discovery rate (FDR). An adjusted $P$-value $<.05$ was considered significant for photoreceptors. For the RPE, an adjusted $P$-value of $<.1$ was considered significant. Additional gene annotation was retrieved from Ensembl (photoreceptors: release 94, RPE: release 98) using the biomaRt R/Bioconductor package. We deposited the RNA-seq data in NCBI's Gene Expression Omnibus. These data are accessible through GEO Series accession number GSE172440 (https://www.ncbi.nlm.nih.gov/ geo/query/acc.cgi?acc=GSE172440). The SubSeries accession numbers of the RPE and photoreceptor RNA-seq data are: GSE172438 (https://www.ncbi.nlm.nih.gov/geo/query/ acc.cgi?acc=GSE172438) and GSE172437 (https://www. ncbi.nlm.nih.gov/geo/query/acc.cgi?acc=GSE172437). Gene ontology and pathway enrichment analyses were performed using $\mathrm{g}$ :Profiler. ${ }^{41}$ We set all identified transcripts in our RNA-seq dataset as a reference background. We set 
an adjusted $P<.05$ as a threshold for significantly enriched pathways using the g:SCS method to correct for multiple testing. ${ }^{41} \mathrm{We}$ investigated interactions between protein products of the list of potential POS phagocytosis candidate genes by STRING analysis. ${ }^{42}$ The 57 candidate genes encode for 49 proteins represented as nodes in the STRING network analysis. By setting the threshold to 0.25 , we found 32 edges in the STRING network. Non-interacting nodes were not shown.

\section{9 | Statistics}

Data are represented as means \pm SEM. Plots were generated using GraphPad Prism (La Jolla, CA, USA), SigmaPlot (Systat Software, San Jose, CA, USA) or R (Bell Labs, Murray Hill, NJ, USA). Normality of distribution was tested using the Shapiro-Wilk test. In case of non-normal distribution, the analysis was performed using ANOVA on ranks. Circadian expression profiles were determined using nonlinear regression fitting to the equation $y=y 0+c \cdot \cos [2 \pi$ $(\mathrm{t}-\phi) / 24]$, where $\mathrm{y} 0$ represents mesor, $\mathrm{c}$ amplitude, and $\phi \mathrm{ac}-$ rophase. ${ }^{43,44}$ The function featured the following constraints: $\phi<24, \phi>0$ and $\mathrm{c}>0$. Gene expression profiles were considered to be rhythmic when significant fitting $(P<.05)$ was observed to the equation $y=y 0+\mathrm{c} \cdot \cos [2 \pi(\mathrm{t}-\phi) / 24]$. Further analyses, where indicated, were performed using 1way or 2-way ANOVA analysis followed by Holm-Sidak's post hoc tests.

\section{3 | RESULTS}

\section{1 | Peak of rod outer segment phagocytosis is blunted in the retinas of Per1 ${ }^{-/-} \operatorname{Per} 2^{B r d m 1}$ mice}

The phagocytosis of photoreceptor outer segments (POS) is a highly rhythmic process occurring at a daily peak. This process persists in constant darkness, suggesting that it is driven by the circadian clock. ${ }^{12,28}$ We tested the hypothesis that intact clockwork is required to sustain a rhythm of POS phagocytosis in constant darkness (DD). To that end, we used the Per1 ${ }^{-/-}$Per $2^{\text {Brdml }}$ clock mutant mice which are behaviorally arrhythmic in DD. ${ }^{21}$

We used age-matched (2 months old) WT and Per1 ${ }^{-/}$Per2 $2^{B r d m l}$ mice, harvested eye globes at 8 -time points over 24 hours and analyzed anti-rhodopsin-stained phagosomes in the RPE (Figure 1A). We quantified POS phagosomes at various time points under DD conditions $(n=3$ animals per genotype and per time point). A 2-way ANOVA analysis showed that the number of POS phagosomes was affected by genotype (WT vs $P e r 1^{-/} P e r 2^{B r d m l}, P<.001$ ), time $(P<.001)$, and an interaction between genotype and time
$(P<.001)$. Post hoc analysis showed that phagocytic activity was rhythmic in WT mice only, with 3-4 times more phagosomes at time point CT1 compared with baseline $(P<.001$ for all time point comparisons) (Figure 1B,C; also confirmed by 1 -way ANOVA, $\left.F_{7,16}=34.49 ; P<.001\right)$. In contrast, in Per1 ${ }^{-1-}$ Per2 ${ }^{\text {Brdml }}$ mice, there was no obvious peak (1-way ANOVA, $\left.F_{7,16}=2.35 ; P=.075\right)$. These results suggest that Perl and/or Per 2 is required for rhythmic POS phagocytosis.

\section{2 $\quad$ Molecular makeup of the retinal clock in the absence of Per1 and Per2}

Since the peak of phagocytosis is attenuated in the mutant mice in DD, we hypothesized that the molecular clockwork is impaired in $\mathrm{Perl}^{-/}$Per2 $2^{\mathrm{Brdml}}$ retinas. To test this hypothesis, we sampled retinas from WT ( $\mathrm{n}=3-4 /$ time point) and $\operatorname{Perl}^{-/} \operatorname{Per}^{\text {Brdml }}$ ( $\mathrm{n}=4-5 /$ time point) mice every 4 hours over 24 hours under DD, and quantified relative mRNA levels of clock genes by qPCR (Figure 2A). Rhythmicity in expression profiles was assessed by cosinor analysis. These changes over the 24 hours cycle were mainly confirmed by 1 way ANOVA analysis (Table S1). We found rhythmic clock gene expression for Bmal1, Per1, Per2, Rev-Erbo, and Rorb in WT whole retinas (Figure $2 \mathrm{~B}$, Table S1). Unexpectedly, we found that in $P e r 1^{-/} P e r 2^{B r d m l}$ mouse retinas also five clock genes were rhythmic: Bmall, Per3, Cry1, Cry 2 and $R e v-E r b \alpha$. Therefore, in contrast to our hypothesis, these results suggest that Perl and Per2 mutations do not significantly impair the rhythmicity of whole retinas in mice.

\section{3 | Transcriptomics analysis of WT mouse RPE and photoreceptors}

To characterize the potential link between the circadian clock and the peak in POS phagocytosis, we first sought to characterize the time-affected transcriptomes of the RPE and photoreceptors. We harvested WT and Per1 ${ }^{-/-}$Per2 $2^{\text {Brdml }}$ mouse eyes kept in DD at 4 time points (CT19, 22, 1, and 10) (Figure 3A). We laser-capture-microdissected the RPE and photoreceptors from each mouse eye, extracted RNA and performed RNA sequencing ( $n=4 /$ genotype/time point for photoreceptors; $n=3$ /genotype/time point for RPE). In the RPE and photoreceptors, respectively, a total of 24382 and 22694 genes had sufficiently large counts to be retained in the statistical analysis. Next, we performed a pair-wise comparison of WT RPE and photoreceptor transcriptomes between consecutive time points (Figure 3B,C). In WT RPE, we found a large number of differentially expressed genes in comparisons between the expected peak in phagocytosis time point CT1 and adjacent time points (CT22 and CT10, respectively, Figure 3B, Table S2). In WT photoreceptors, 


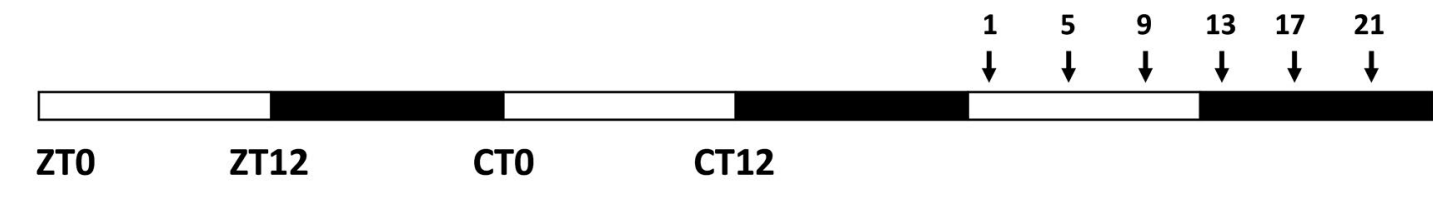

(B)

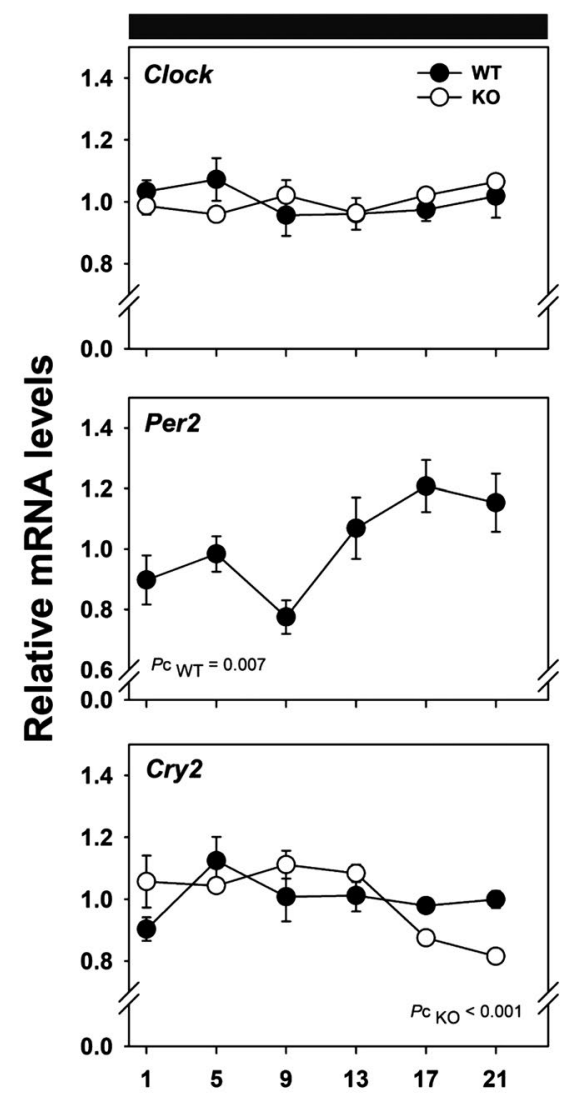

CT (h)
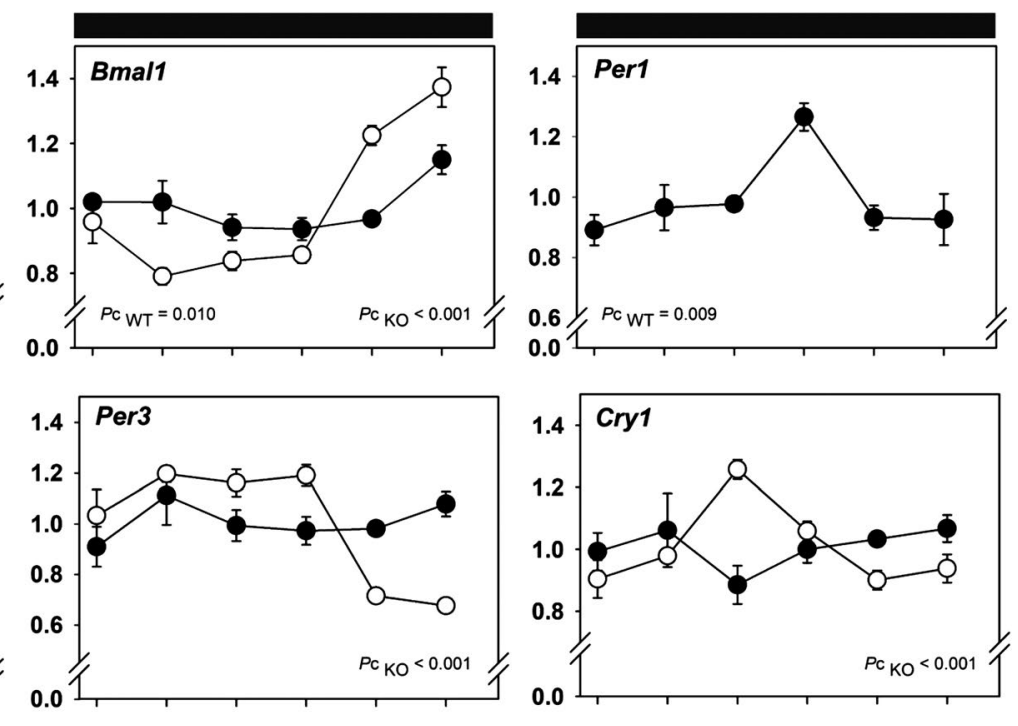

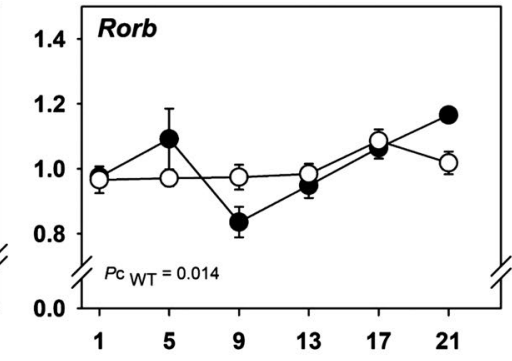

CT (h)

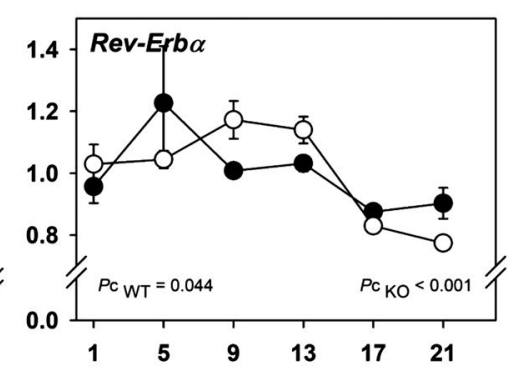

CT (h)

F I G U RE 2 Clock gene expression profiles in WT (black dots) and Perl ${ }^{-/}{ }^{-}$er $2^{\text {Brdml }}$ (white dots; KO) whole retinas under DD conditions. A, Mice were placed under DD conditions, sacrificed at time points indicated by arrows and their whole retinas were harvested. B, QPCR analysis revealed that rhythmic gene expression was observed for Bmall, Per1, Per2, Rev-Erb $\alpha$, and Rorb in WT retinas. Rhythmic expression was found for Bmal1, Per3, Cry1, Cry2, and Rev-Erb $\alpha$ in Per1 ${ }^{-/-} \operatorname{Per}^{\text {Brdml }}$ retinas. Values represent mean \pm SEM. Significant temporal variations are indicated $(P<.05) . P c-p$-value of cosinor non-linear regression fitting to the equation $y=y 0+\mathrm{c} \cdot \cos [2 \pi(\mathrm{t}-\Phi) / 24]$, with y0 - mesor, camplitude, and $\Phi$-acrophase. $\mathrm{N}=3-4$ for WT and 4-5 for double mutants/time point

most genes are differentially expressed in comparisons between CT10 and adjacent time points (CT1 and CT19, respectively, Figure 3C, Table S3). In contrast, in all pair-wise comparisons, we found that only three genes differed significantly between time points (ie, were upregulated at CT10 vs 19) in $\mathrm{Perl}^{-/-} \mathrm{Per} 2^{\mathrm{Brdml}}$ RPE. We found that one gene was downregulated at CT19 vs CT10 in Per1 ${ }^{-/-} \mathrm{Per}^{\mathrm{Brdml}}$ photoreceptors. Thus, these results suggest that the transcriptional program for initiating POS phagocytosis is likely in the RPE and not photoreceptors.

Our differential expression analysis showed that 594 genes in WT RPE $(=2.44 \%$ of all genes retained in the analysis) and 2372 genes in WT photoreceptors $(=10.45 \%$ of retained genes) varied over time points (Figure 3D,
Tables S4 and S5). Among them are components of the circadian clock network (Tables S4 and S5). Pathway analysis of time-affected genes in WT mice RPE revealed that, in addition to circadian pathways, phototransduction and metabolic-related pathways were functionally enriched (Table S6). We also performed pathway analyses of differentially expressed RPE genes between adjacent time points (Table S7). The highest number of functionally enriched terms was found in downregulated RPE genes at CT10 compared to CT1, among which the most significantly enriched terms were axon, distal axon, presynapse, and glycolysis and gluconeogenesis (Table S7).

Time-affected WT photoreceptor genes were enriched in circadian, metabolic, neurotransmission, and DNA 


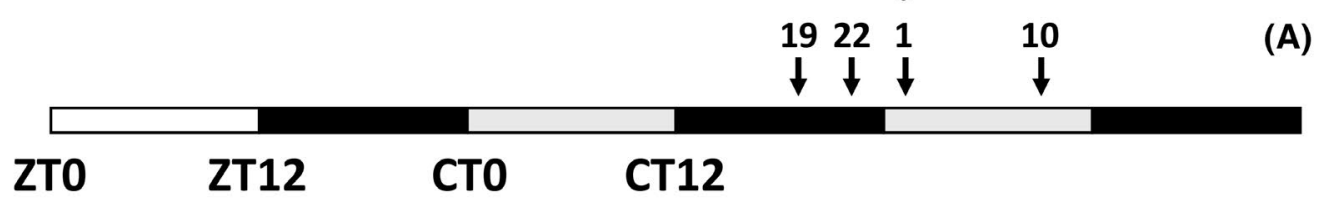

RPE

WT CT 22 vs CT1 1 WT CT10 vs CT1

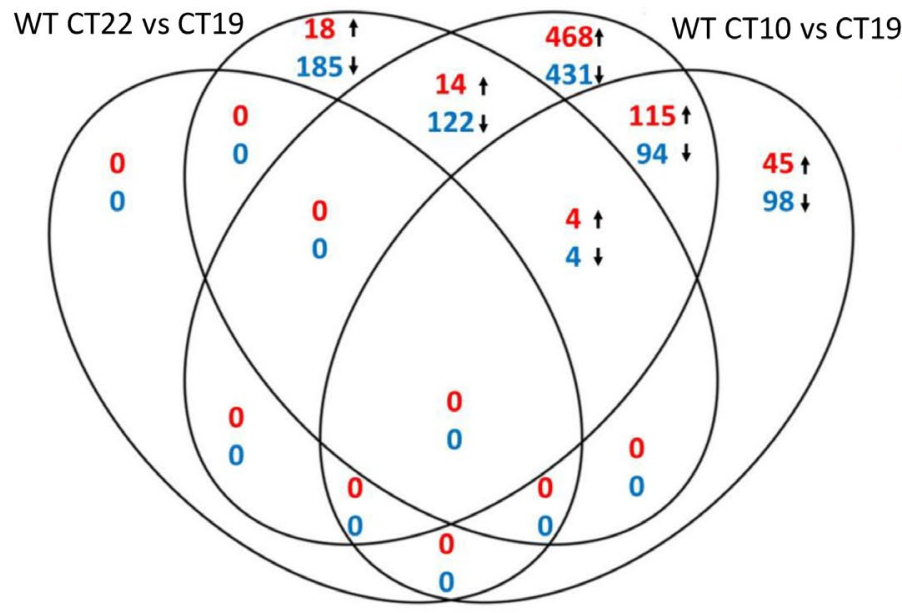

PR

(C)

WT CT 22 vs CT 1 WT CT 10 vs CT 1

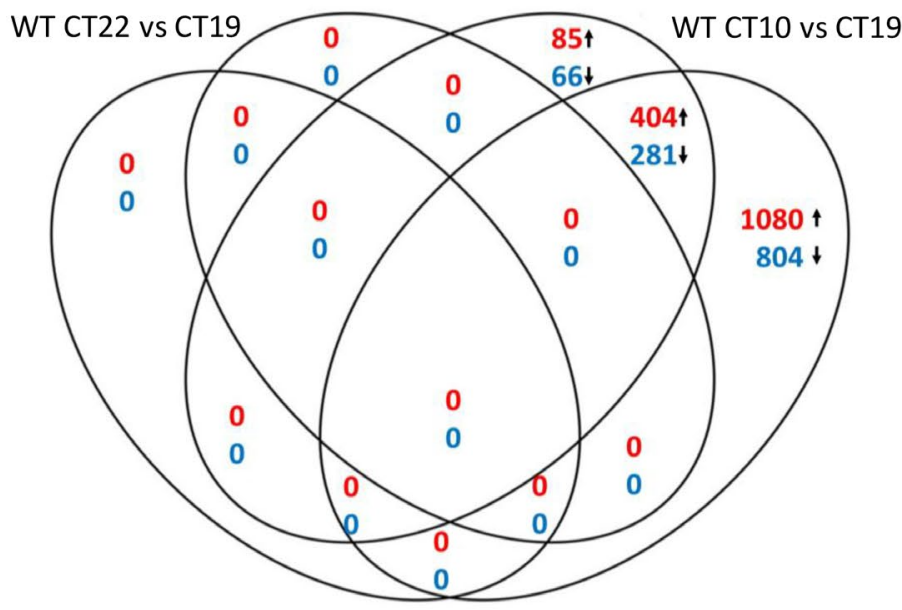

(B)
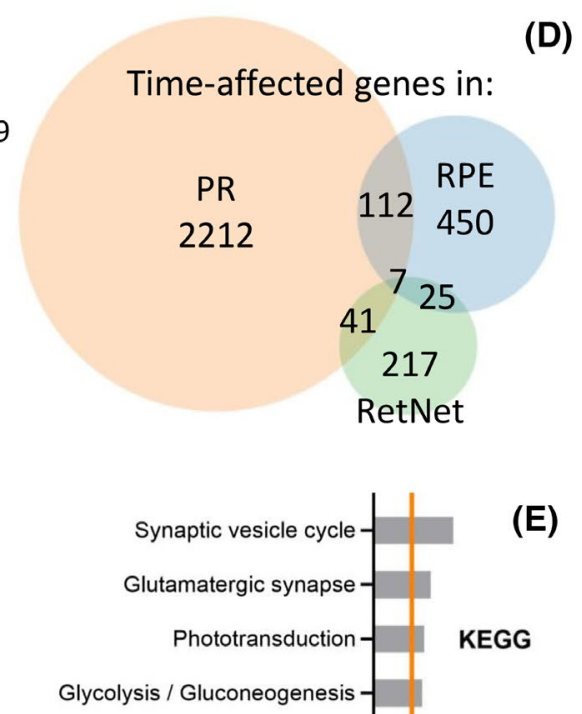

(E)
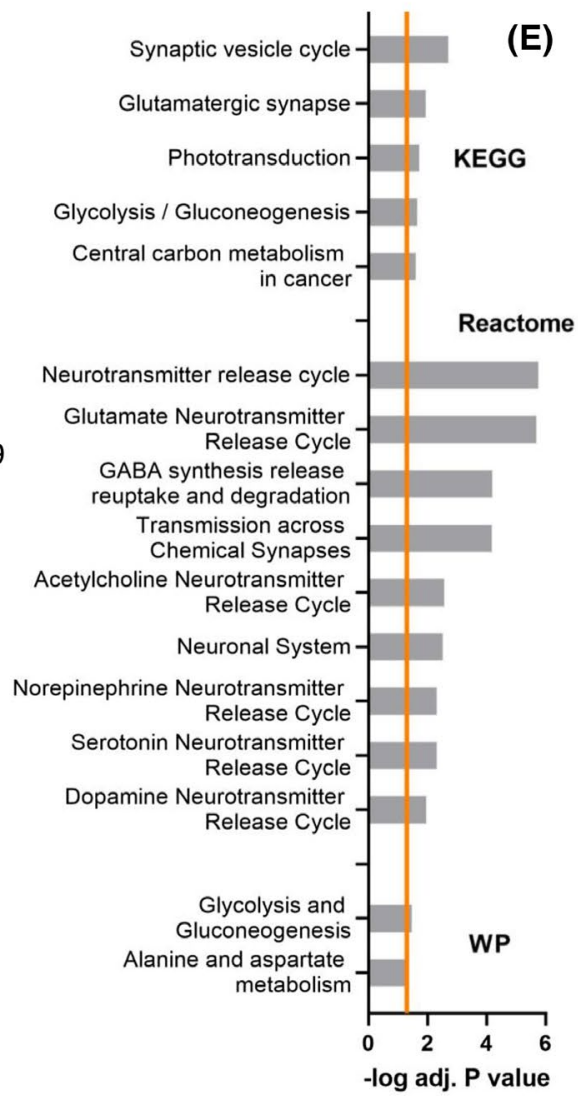

F I G U RE 3 Transcriptional profiling of WT mouse RPE and photoreceptors. A, Eyes were obtained under DD conditions from four successive time points: before (CT19, CT22), during (CT1), and after (CT10) the expected peak in POS phagocytosis (n = 4/time point). RPE and photoreceptors were meticulously laser-capture-microdissected from each mouse eye, RNA was extracted and the transcriptomes were determined using RNA-sequencing. B, In the RPE ( $n=4$ pooled to 3/time point), a substantial number of genes were differentially expressed at time points adjacent to the peak in POS phagocytosis-CT1. Detailed lists of differentially expressed RPE genes are shown in Table S2. C, In contrast, in photoreceptors (PR) most differential gene expression occurs around CT10 ( $\mathrm{n}=4$ /time point). Detailed lists of differentially expressed PR genes are shown in Table S3. Red numbers represent the number of upregulated differentially expressed genes, whereas blue ones are downregulated. D, A substantial number of identified transcripts showed a time effect in WT PR and RPE. There is considerable overlap $(n=119)$ between timeaffected genes in these two tissues, a number of which overlap with the RetNet list of eye disease-related genes. ${ }^{45}$ Detailed lists of these genes are shown in Table S12. E, Functional annotation (performed using g:Profiler) revealed that overlapping time-affected genes in RPE and PR are enriched in glucose metabolism and neurotransmission-related pathways. The orange line represents the significance level cut-off (adjusted $P<.05$ ). WikiPathways (WP), Reactome, and KEGG are databases of biological pathways 
repair-related pathways (Table S8). Notably, DNA-repairrelated pathways were enriched in photoreceptor genes upregulated at CT10 compared to adjacent time points (CT19 and CT1). These terms include: DNA repair, helicase activity, cellular response to DNA damage stimulus, response to radiation, among many others (Table S9). Interestingly, 119 time-affected genes overlap in RPE and photoreceptors (Table S10), and are functionally enriched in glucose metabolism and neurotransmitter releaserelated pathways (Figure 3E, Table S11). We also found that, respectively, 32 and 48 time-affected genes in the RPE and photoreceptors overlap with the RetNet list of eye disease-related genes ${ }^{45}$ (Figure 3D, Table S12). Thus, our results show that in the RPE and photoreceptors, a large number of genes and pathways vary in a time-dependent manner, a number of which are implicated in eye diseases.

\section{4 | Potential molecular pathway that initiates POS phagocytosis}

Our results suggested that the transcriptional events in the RPE might initiate POS phagocytosis (Figure 3B). Our results also suggested that Per 1 and/or Per 2 are necessary for driving the peak in POS phagocytosis under DD (Figure 1), but the molecular link is unclear. To characterize this link, we performed pair-wise comparisons between WT and Per ${ }^{-/-}$Per $2^{\text {Brdml }}$ RPE transcriptomes. We found a substantial number of genes that were differentially expressed in Per1 ${ }^{-/}$Per2 ${ }^{\text {Brdml }}$ RPE compared to WT ones at the peak POS phagocytosis time point CT1 (Figure 4A). Next, we defined selection criteria for genes that potentially initiate POS phagocytosis (Figure 4B). Considering that the peak in POS phagocytosis is lacking in $\mathrm{Per}{ }^{-/-} \mathrm{Per} 2^{\mathrm{Brdml}}$ mice, we assumed that the genes that initiate POS phagocytosis are downregulated in double mutant RPE compared to WT ones at CT1. POS phagocytosis occurs as a peak in WT mice on a molecular and functional level. ${ }^{46,47}$ Thus, we selected genes that are both upregulated at CT1 vs CT22 and downregulated at CT10 vs CT1 in WT RPE. We removed possible photoreceptor "contaminants" from this list by mouse signature cone and rod genes ${ }^{48}$ and the Gene Ontology database (POS cellular component, GO:0001750). Using this strategy, we obtained a list of 57 candidate genes (Figure 4B, Table 2). These genes are functionally enriched in neurotransmission-related pathways (Figure 4C, Table S13). To reveal the interactions that protein products of these genes are involved in, we constructed a proteinprotein interaction network using STRING ${ }^{42}$ (Figure 4D). Our list revealed a number of functional associations in which the protein products of candidate genes are involved in, most of which are associated with the term cell junction (highlighted in red in Figure 4D). This cluster involves the interactions of Syp, Gnaz, Pacsin1, Snap91, Camk2d, and Camk $2 b$ as identified in our STRING analysis. Thus, POS phagocytosis might be initiated by the largest cluster identified in this analysis.

\section{4 | DISCUSSION}

In the present study, we found no peak in POS phagocytosis in the retinas of mice carrying a combined Perl and Per2 mutation under constant darkness. Unexpectedly, gene expression analysis revealed that mutant retinas remained rhythmic under constant darkness, in contrast to mutant RPE and photoreceptors which showed no temporal variation. Using the purest possible RPE and photoreceptor sample material obtained by microdissection, we found significant differential gene expression in WT RPE at the peak phagocytosis time point, but not in photoreceptors. Our results suggest a network of genes that potentially initiates POS phagocytosis in the RPE. These data cast doubts on the view that molecular events in photoreceptors drive POS phagocytosis (via expression of phosphatidylserine "eat-me" signals). ${ }^{18}$

Retinal clocks are present in virtually all retinal layers ${ }^{4,49-51}$ and are tightly coupled. ${ }^{4}$ Coupling between retinal clocks contributes toward the precise timing of physiology within the retina. ${ }^{52}$ In our study, in $\mathrm{Perl}^{-/-} \mathrm{Per} 2^{\mathrm{Brdml}}$ mice, constant darkness prevented any increased phagocytosis following the subjective onset of day, a process known to be clock-regulated. ${ }^{12,53-56}$ Thus, we speculated that constant darkness might impair the clockwork in $\mathrm{Per}^{-/-} \mathrm{Per} 2^{\mathrm{Brdm} 1}$ whole retinas. The literature is not consistent regarding the effects of lighting conditions on clock gene expression in the whole retina. Studies either report no effects of DD on global retinal oscillations ${ }^{51,57}$ or suggest that DD conditions dampen retinal rhythmicity. ${ }^{44,58,59}$ Unexpectedly, our qPCR study revealed that clock gene expression remained rhythmic in both WT and $P e r 1^{-/} \mathrm{Per}^{\mathrm{Brdml}}$ whole retinas. The origin of rhythmicity in mutant whole retinas is not known. It is most likely not due to input from the central clock, because retinal clocks are known to be independent of the $\mathrm{SCN}^{3}$ and the $\mathrm{SCN}$ is considered arrhythmic based on the locomotor activity of $\mathrm{Perl}^{-/} \mathrm{Per} 2^{\mathrm{Brdml}}$ mice in DD. ${ }^{21}$ The source is most likely not in photoreceptors because, in this study, transcriptomics analysis of LCM-isolated $\mathrm{Perl}^{-/} \mathrm{Per}^{\mathrm{Brdml}}$ photoreceptors showed no temporal variations. Therefore, it is likely that rhythms in mutant whole retinas originate from retinal layers which display the most robust rhythms: eg, the inner retina. ${ }^{4,44,49,50,57}$ Considering that the number of oscillating genes differs considerably across mouse organs/tissues, ${ }^{60}$ Perl and/or Per2 mutations may impact the RPE and photoreceptor clocks disproportionally more than the clockwork 

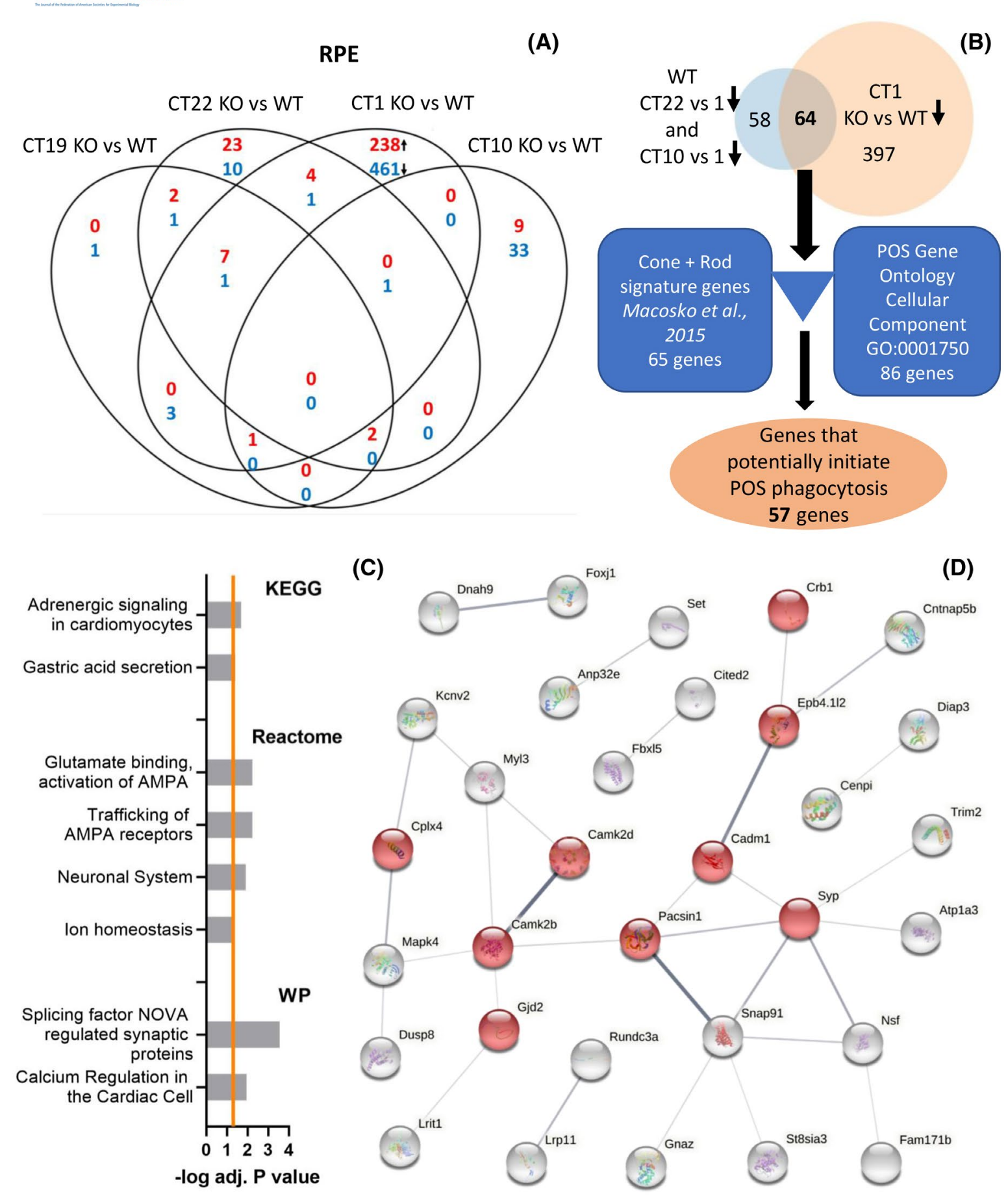

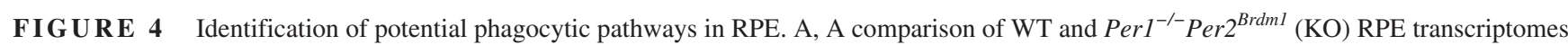
within each time point revealed that most genes were differentially expressed during the peak phagocytosis time point—CT1. Red numbers represent the number of upregulated differentially expressed genes, whereas blue ones are downregulated. B, Selection strategy for compiling the list of genes in the RPE possibly implicated in regulating POS phagocytosis. Signature rod and cone genes ${ }^{48}$ and the Gene Ontology term "Photoreceptor Outer Segment" were used to remove photoreceptor genes from the list of genes that potentially regulate POS phagocytosis. C, Functional enrichment analysis using g:Profiler showed that these genes are enriched in neurotransmission-related pathways from the WP, Reactome, KEGG databases. The orange line represents the significant cut-off (adjusted $P<.05$ ). D, STRING network analysis of protein functional associations of products of RPE genes implicated in initiating phagocytosis. Nodes represent protein products $(\mathrm{n}=57)$. Disconnected nodes are not shown. Edges represent protein functional associations. Interaction confidence scores range 0.25-0.99

of other retinal cells. Regardless of the reasons, these results suggest that (global) retinal rhythmicity is not sufficient for driving the peak of POS phagocytosis.
The phagocytosis of POS is a rhythmic process occurring roughly 1 hour after light onset. ${ }^{12,53-56}$ This process is critical for retinal health as demonstrated by retinal degeneration 
T A B L E 2 List of RPE genes potentially involved in initiating the peak in POS phagocytosis

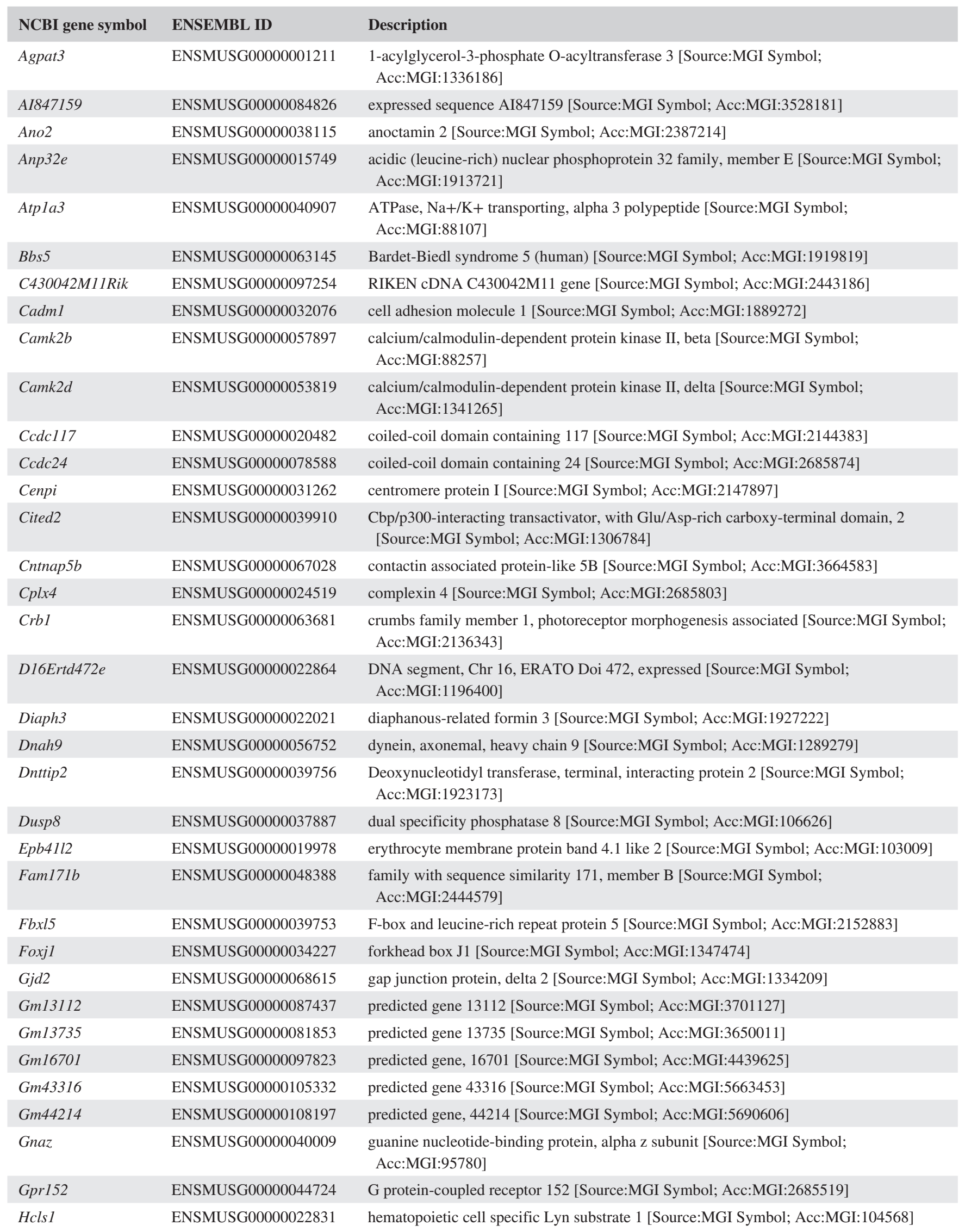


T A B L E 2 (Continued)

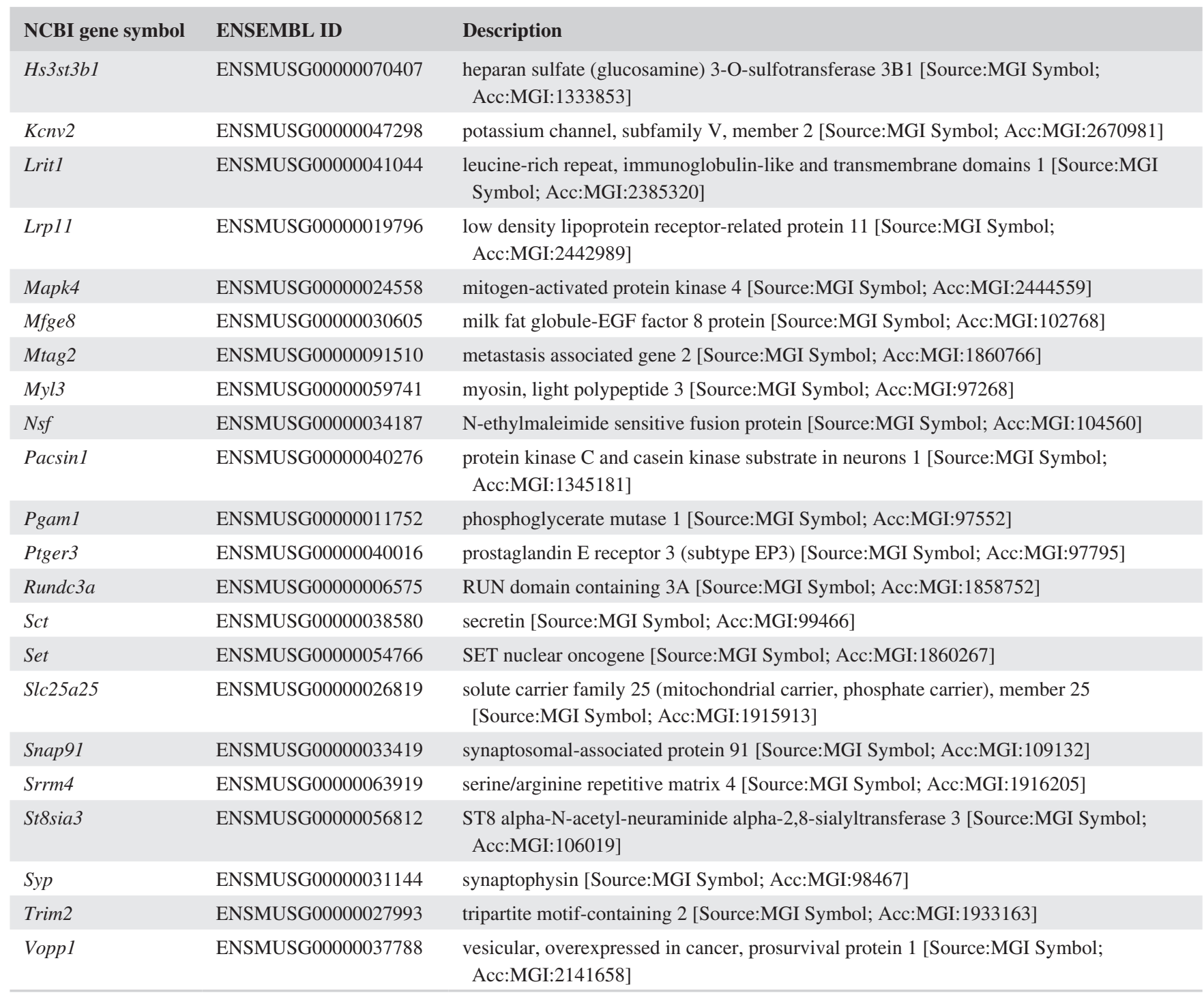

displayed in both human patients ${ }^{16}$ and animal models. ${ }^{15,30,61}$ Some literature stresses the importance of precise timing of POS phagocytosis in maintaining retinal health. ${ }^{30,61}$ This view is corroborated by our finding that a number of eye disease-related genes vary across time points in the RPE and photoreceptors. However, it was recently reported that dopamine D2 receptor knockout mice had no peak in POS phagocytosis and displayed no apparent retinal pathologies. ${ }^{29}$ Regardless, the molecular pathways responsible for driving this peak are not known. ${ }^{5,17,18}$ By immunohistochemistry and quantifying ingested POS in clock mutant mouse retinas, we showed that Perl and/or Per2 are necessary (molecular clock) components for the transient surge in POS phagocytosis.

The prevailing view is that POS phagocytosis is initiated by the externalization of phosphatidylserine "eat-me" signals on the POS membrane. ${ }^{17,18}$ However, we found that microdissected WT photoreceptors did not differ in gene expression $3 \mathrm{~h}$ or $6 \mathrm{~h}$ before the peak in POS phagocytosis. This view is also disputed by recent work showing that the POS phagocytosis peak persists in mice carrying a retina-specific (Chx10 ${ }^{\text {Cre }}$-driven) knockout of Bmall. ${ }^{62}$ In contrast, in WT RPE, we found that a number of genes were differentially expressed at the phagocytic peak time point compared to the $3 \mathrm{~h}$ earlier one. In addition, at the peak phagocytosis time point, we found a vast number of differentially expressed genes in $P e r 1^{-/}$Per $2^{\text {Brdml }}$ RPE compared to WT ones. These results suggest that POS phagocytosis is initiated by the RPE. This possibility is, indeed, plausible because the RPE was shown to display sustained rhythms in various models: in vivo, ${ }^{29,63-66}$ ex vivo, ${ }^{67-69}$ and in cell culture models. ${ }^{69-73}$ Importantly, the phagocytic machinery is rhythmic in these cells. ${ }^{29,47,69,72}$ Furthermore, there was no rhythm of phagocytic activity in an arrhythmic BMAL1 knockout RPE cell culture model ${ }^{72}$ and in a conditional RPE-specific Bmall knockout mouse model. ${ }^{62}$ Thus, the literature together with our data supports the view that the clock in the RPE controls 
the morning peak of POS phagocytosis. However, photoreceptors may still initiate POS phagocytosis via yet unidentified post-transcriptional pathways.

Finally, we proposed a network of genes for regulating ROS phagocytosis in the RPE. The candidate genes in this list are enriched in the ion homeostasis pathway. This is expected as previous studies implicated ion channels in POS phagocytosis such as voltage-gated sodium channels ${ }^{74}$ and the Ltype calcium channel $\mathrm{Ca}_{\mathrm{v}} 1.3{ }^{61}$ The list also contains known genes implicated in POS phagocytosis such as $\mathrm{Mfge}^{75}$ and $M y l 3{ }^{76}$ Cell junctions were also enriched in the candidate gene list, among which $G j d 2$ encodes for a gap junction protein. Increased gap junction expression may enhance the connectivity of the RPE at the peak phagocytic time point. That might, in turn, lead to a synchronized and sharp phagocytic peak across the whole RPE. However, it should also be noted that a number of genes in the list have not been sufficiently characterized, eg, Gm13112, Gm13735, Gm16701, etc. Therefore, our list of candidate genes provides ample opportunities for investigation for the research community.

The strength of this approach is the use of the purest possible sample material obtained from LCM. In addition, we considered the rhythmic nature of POS phagocytosis by samples from multiple time points. We also compared our results with an arrhythmic mouse model that lacked this peak phagocytic activity. There are some limitations in our approach. For example, the genes implicated in initiating phagocytosis might not be downregulated after the peak phagocytic time-point. It might be that at the peak phagocytic time point, the downregulated genes repress RPE phagocytic activity. It is also possible that genes in the list might be "contaminants" originating from POS fragments that are ingested by the RPE. Despite the imperfections, this list will be a valuable tool for studying the POS phagocytosis pathway.

In conclusion, our study reveals that Per1/Per2 are necessary circadian clock components for driving the rhythm of POS phagocytosis. Our results show that Per1 and Per2 mutations do not impair the rhythmicity of the whole retina. Our data suggest that the molecular pathways that initiate POS phagocytosis are most likely initiated by the RPE by genes functionally enriched in neurotransmissionrelated pathways.

\section{ACKNOWLEDGMENTS}

We thank Anneloor LMA ten Asbroek and Nguyen-Vy Vo for technical assistance. We thank Dr D. Sage, Dr S. Reibel and N. Lethenet from the Chronobiotron (UMS 3415) for animal care and Dr U. Albrecht (University of Freiburg) for the $\mathrm{Perl}^{-/-} \mathrm{Per}^{\mathrm{Brdml}}$ mice. This project has been funded with support from the NeuroTime Erasmus+ grant (European Union), Rotterdamse Stichting Blindenbelangen (Netherlands), Nelly Reef fund (Netherlands), Stichting voor Ooglijders (Netherlands), Stichting tot Verbetering van het Lot der Blinden (Netherlands), and Retina France (France).

\section{CONFLICT OF INTEREST}

The authors declare no competing interests.

\section{AUTHOR CONTRIBUTIONS}

N. Milićević performed experiments, analysis, prepared figures, wrote the manuscript, and obtained funding; $\mathrm{O}$. Ait-Hmyed Hakkari performed experiments, data analysis, prepared figures, and obtained funding; P.D. Moerland and A. Jongejan performed bioinformatics analysis and edited the manuscript; U. Bagchi, J.B. ten Brink, and C. Sandu provided technical assistance, performed experiments, prepared figures, and edited the manuscript; D. Hicks, A.A. Bergen, and M.-P. Felder-Schmittbuhl conceptualized and directed the project, obtained funding, provided resources, performed analysis, and edited the manuscript.

\section{ORCID}

Nemanja Milićević (iD https://orcid. org/0000-0002-8062-7270

Udita Bagchi (iD https://orcid.org/0000-0001-7726-0319

Cristina Sandu (D) https://orcid.org/0000-0001-8836-5837

Aldo Jongejan (iD https://orcid.org/0000-0002-8948-2549

Perry D. Moerland (D) https://orcid.

org/0000-0002-2357-3659

Arthur A. Bergen (D) https://orcid.org/0000-0002-6333-9576

Marie-Paule Felder-Schmittbuhl (iD) https://orcid.

org/0000-0003-3539-1243

\section{REFERENCES}

1. Stratmann M, Schibler U. Properties, entrainment, and physiological functions of mammalian peripheral oscillators. J Biol Rhythms. 2006;21:494-506.

2. Ko CH, Takahashi JS. Molecular components of the mammalian circadian clock. Hum Mol Genet. 2006;15 Spec No 2:R271-R277.

3. Terman JS, Reme CE, Terman M. Rod outer segment disk shedding in rats with lesions of the suprachiasmatic nucleus. Brain Res. 1993;605:256-264.

4. Jaeger C, Sandu C, Malan A, Mellac K, Hicks D, Felder-Schmittbuhl MP. Circadian organization of the rodent retina involves strongly coupled, layer-specific oscillators. FASEB J. 2015;29:1493-1504.

5. McMahon DG, Iuvone PM, Tosini G. Circadian organization of the mammalian retina: from gene regulation to physiology and diseases. Prog Retin Eye Res. 2014;39:58-76.

6. Besharse JC, Iuvone PM. Circadian clock in Xenopus eye controlling retinal serotonin N-acetyltransferase. Nature. 1983;305:133-135.

7. Tosini G, Menaker M. Circadian rhythms in cultured mammalian retina. Science. 1996;272:419-421.

8. Ribelayga C, Cao Y, Mangel SC. The circadian clock in the retina controls rod-cone coupling. Neuron. 2008;59:790-801.

9. Ribelayga C, Mangel SC. Identification of a circadian clockcontrolled neural pathway in the rabbit retina. PLOS ONE. 2010;5:e11020. 
10. Bassi CJ, Powers MK. Daily fluctuations in the detectability of dim lights by humans. Physiol Behav. 1986;38:871-877.

11. Barnard AR, Hattar S, Hankins MW, Lucas RJ. Melanopsin regulates visual processing in the mouse retina. Curr Biol. 2006;16:389-395.

12. LaVail MM. Rod outer segment disk shedding in rat retina: relationship to cyclic lighting. Science. 1976;194:1071-1074.

13. Ko GY. Circadian regulation in the retina: from molecules to network. Eur J Neuorsci. 2018;51:194-216.

14. Kevany BM, Palczewski K. Phagocytosis of retinal rod and cone photoreceptors. Physiology. 2010;25:8-15.

15. D'Cruz PM, Yasumura D, Weir J, et al. Mutation of the receptor tyrosine kinase gene Mertk in the retinal dystrophic RCS rat. Hum Mol Genet. 2000;9:645-651.

16. Gal A, Li Y, Thompson DA, et al. Mutations in MERTK, the human orthologue of the RCS rat retinal dystrophy gene, cause retinitis pigmentosa. Nat Genet. 2000;26:270-271.

17. Mazzoni F, Safa H, Finnemann SC. Understanding photoreceptor outer segment phagocytosis: use and utility of RPE cells in culture. Exp Eye Res. 2014;126:51-60.

18. Müller C, Finnemann SC. RPE Phagocytosis. In: Klettner AK, Dithmar S, eds. Retinal Pigment Epithelium in Health and Disease. Cham: Springer International Publishing; 2020:47-63.

19. Bobu C, Craft CM, Masson-Pevet M, Hicks D. Photoreceptor organization and rhythmic phagocytosis in the nile rat Arvicanthis ansorgei: a novel diurnal rodent model for the study of cone pathophysiology. Invest Ophthalmol Vis Sci. 2006;47:3109-3118.

20. Krigel A, Felder-Schmittbuhl MP, Hicks D. Circadian-clock driven cone-like photoreceptor phagocytosis in the neural retina leucine zipper gene knockout mouse. Mol Vis. 2010;16:2873-2881.

21. Zheng B, Albrecht U, Kaasik K, et al. Nonredundant roles of the mPer1 and mPer2 genes in the mammalian circadian clock. Cell. 2001;105:683-694.

22. Zheng B, Larkin DW, Albrecht U, et al. The mPer2 gene encodes a functional component of the mammalian circadian clock. Nature. 1999;400:169-173.

23. Albrecht U, Zheng B, Larkin D, Sun ZS, Lee CC. MPer1 and mper2 are essential for normal resetting of the circadian clock. $J$ Biol Rhythms. 2001;16:100-104.

24. Hicks D, Molday RS. Differential immunogold-dextran labeling of bovine and frog rod and cone cells using monoclonal antibodies against bovine rhodopsin. Exp Eye Res. 1986;42:55-71.

25. Mazzoni F, Mao Y, Finnemann SC. Advanced analysis of photoreceptor outer segment phagocytosis by RPE cells in culture. Methods Mol Biol. 2019;1834:95-108.

26. Farkas MH, Lew DS, Sousa ME, et al. Mutations in pre-mRNA processing factors 3,8 , and 31 cause dysfunction of the retinal pigment epithelium. Am J Pathol. 2014;184:2641-2652.

27. Esposito NJ, Mazzoni F, Vargas JA, Finnemann SC. Diurnal photoreceptor outer segment renewal in mice is independent of galectin-3. Invest Ophthalmol Vis Sci. 2021;62:7.

28. Bobu C, Hicks D. Regulation of retinal photoreceptor phagocytosis in a diurnal mammal by circadian clocks and ambient lighting. Invest Ophthalmol Vis Sci. 2009;50:3495-3502.

29. Goyal V, DeVera C, Laurent V, et al. Dopamine 2 receptor signaling controls the daily burst in phagocytic activity in the mouse retinal pigment epithelium. Invest Ophthalmol Vis Sci. 2020;61:10.

30. Laurent V, Sengupta A, Sánchez-Bretaño A, Hicks D, Tosini G. Melatonin signaling affects the timing in the daily rhythm of phagocytic activity by the retinal pigment epithelium. Exp Eye Res. 2017;165:90-95.

31. Wilson $\mathrm{T}$. The role of the pinhole in confocal imaging system. In: Pawley JB, eds. Handbook of biological confocal microscopy. Boston, MA: Springer; 1995:167-182. https://doi. org/10.1007/978-1-4757-5348-6_11

32. Hellemans J, Mortier G, De Paepe A, Speleman F, Vandesompele J. qBase relative quantification framework and software for management and automated analysis of real-time quantitative PCR data. Genome Biol. 2007;8(2):R19. https://doi.org/10.1186/ gb-2007-8-2-r19

33. Hiragaki S, Baba K, Coulson E, Kunst S, Spessert R, Tosini G. Melatonin signaling modulates clock genes expression in the mouse retina. PLoS ONE. 2014;9:e106819.

34. Sayols S, Scherzinger D, Klein H. dupRadar: a Bioconductor package for the assessment of PCR artifacts in RNA-Seq data. BMC Bioinformat. 2016;17(1):428. https://doi.org/10.1186/s1285 9-016-1276-2

35. Bolger AM, Lohse M, Usadel B. Trimmomatic: a flexible trimmer for Illumina sequence data. Bioinformatics. 2014;30:2114-2120.

36. Kim D, Langmead B, Salzberg SL. HISAT: a fast spliced aligner with low memory requirements. Nat Methods. 2015;12:357-360.

37. Anders S, Pyl PT, Huber W. HTSeq-a Python framework to work with high-throughput sequencing data. Bioinformatics. 2015;31:166-169.

38. Robinson MD, McCarthy DJ, Smyth GK. edgeR: a Bioconductor package for differential expression analysis of digital gene expression data. Bioinformatics. 2010;26:139-140.

39. Ritchie ME, Phipson B, Wu D, et al. limma powers differential expression analyses for RNA-sequencing and microarray studies. Nucleic Acids Res. 2015;43:e47.

40. Law CW, Chen Y, Shi W, Smyth GK. voom: precision weights unlock linear model analysis tools for RNA-seq read counts. Genome Biol. 2014;15(2):R29. https://doi.org/10.1186/gb-2014-15-2-r29

41. Reimand J, Kull M, Peterson H, Hansen J, Vilo J. g:Profiler-a web-based toolset for functional profiling of gene lists from largescale experiments. Nucleic Acids Res. 2007;35:W193-W200.

42. Szklarczyk D, Franceschini A, Wyder S, et al. STRING v10: protein-protein interaction networks, integrated over the tree of life. Nucleic Acids Res. 2015;43:D447-D452.

43. Nelson W, Tong YL, Lee JK, Halberg F. Methods for cosinorrhythmometry. Chronobiologia. 1979;6:305-323.

44. Sandu C, Hicks D, Felder-Schmittbuhl MP. Rat photoreceptor circadian oscillator strongly relies on lighting conditions. Eur J Neuorsci. 2011;34:507-516.

45. Daiger SP, Rossiter BJF, Greenberg J, Christoffels A, Hide W. Data services and software for identifying genes and mutations causing retinal degeneration. Invest Ophthalmol Vis Sci. 1998;39: S295.

46. Law AL, Parinot C, Chatagnon J, et al. Cleavage of Mer tyrosine kinase (MerTK) from the cell surface contributes to the regulation of retinal phagocytosis. J Biol Chem. 2015;290:4941-4952.

47. Nandrot EF, Kim Y, Brodie SE, Huang X, Sheppard D, Finnemann SC. Loss of synchronized retinal phagocytosis and age-related blindness in mice lacking alphavbeta5 integrin. J Exp Med. 2004;200:1539-1545.

48. Macosko EZ, Basu A, Satija R, et al. Highly parallel genome-wide expression profiling of individual cells using nanoliter droplets. Cell. 2015;161:1202-1214. 
49. Ruan GX, Zhang DQ, Zhou T, Yamazaki S, McMahon DG. Circadian organization of the mammalian retina. Proc Natl Acad Sci USA. 2006;103:9703-9708.

50. Ruan GX, Allen GC, Yamazaki S, McMahon DG. An autonomous circadian clock in the inner mouse retina regulated by dopamine and GABA. PLoS Biol. 2008;6:e249.

51. Liu X, Zhang Z, Ribelayga CP. Heterogeneous expression of the core circadian clock proteins among neuronal cell types in mouse retina. PLOS ONE. 2012;7:e50602.

52. Felder-Schmittbuhl MP, Buhr ED, Dkhissi-Benyahya O, et al. Ocular clocks: adapting mechanisms for eye functions and health. Invest Ophthalmol Vis Sci. 2018;59:4856-4870.

53. LaVail MM. Circadian nature of rod outer segment disc shedding in the rat. Invest Ophthalmol Vis Sci. 1980;19:407-411.

54. Young RW. The renewal of rod and cone outer segments in the rhesus monkey. J Cell Biol. 1971;49:303-318.

55. Young RW. The daily rhythm of shedding and degradation of rod and cone outer segment membranes in the chick retina. Invest Ophthalmol Vis Sci. 1978;17:105-116.

56. Fisher SK, Pfeffer BA, Anderson DH. Both rod and cone disc shedding are related to light onset in the cat. Invest Ophthalmol Vis Sci. 1983;24:844-856.

57. Zhang DQ, Zhou T, Ruan GX, McMahon DG. Circadian rhythm of Period 1 clock gene expression in NOS amacrine cells of the mouse retina. Brain Res. 2005;1050:101-109.

58. Storch KF, Paz C, Signorovitch J, et al. Intrinsic circadian clock of the mammalian retina: importance for retinal processing of visual information. Cell. 2007;130:730-741.

59. Bobu C, Sandu C, Laurent V, Felder-Schmittbuhl MP, Hicks D. Prolonged light exposure induces widespread phase shifting in the circadian clock and visual pigment gene expression of the Arvicanthis ansorgei retina. Mol Vis. 2013;19:1060-1073.

60. Zhang R, Lahens NF, Ballance HI, Hughes ME, Hogenesch JB. A circadian gene expression atlas in mammals: implications for biology and medicine. Proc Natl Acad Sci USA. 2014;111:16219-16224.

61. Muller C, Mas Gomez N, Ruth P, Strauss O. CaV1.3 L-type channels, maxiK $\mathrm{Ca}(2+)$-dependent $\mathrm{K}(+)$ channels and bestrophin-1 regulate rhythmic photoreceptor outer segment phagocytosis by retinal pigment epithelial cells. Cell Signal. 2014;26:968-978.

62. DeVera C, Dixon J, Chrenek MA, Baba K, Iuvone PM, Tosini G. The circadian clock in the retinal pigment epithelium controls the diurnal rhythm of phagocytic activity. bioRxiv. 2020. https://doi. org/10.1101/2020.12.02.408799

63. Louer EMM, Yi G, Carmone C, et al. Genes involved in energy metabolism are differentially expressed during the day-night cycle in murine retinal pigment epithelium. Invest Ophthalmol Vis Sci. 2020;61:49.

64. Louer EMM, Gunzel D, Rosenthal R, et al. Differential day-night expression of tight junction components in murine retinal pigment epithelium. Exp Eye Res. 2020;193:107985.

65. DeVera C, Tosini G. Circadian analysis of the mouse retinal pigment epithelium transcriptome. Exp Eye Res. 2020;193:107988.

66. Mure LS, Le HD, Benegiamo G, et al. Diurnal transcriptome atlas of a primate across major neural and peripheral tissues.
Science. 2018;359(6381):eaao0318. https://doi.org/10.1126/scien ce.aao0318

67. Baba K, Sengupta A, Tosini M, Contreras-Alcantara S, Tosini G. Circadian regulation of the PERIOD 2:LUCIFERASE bioluminescence rhythm in the mouse retinal pigment epithelium-choroid. Mol Vis. 2010;16:2605-2611.

68. Baba K, DeBruyne JP, Tosini G. Dopamine 2 receptor activation entrains circadian clocks in mouse retinal pigment epithelium. Sci Rep. 2017;7(1):5103. https://doi.org/10.1038/s41598-017-05394-x

69. Milicevic N, Mazzaro N, de Bruin I, et al. Rev-Erbalpha and photoreceptor outer segments modulate the circadian clock in retinal pigment epithelial cells. Sci Rep. 2019;9:11790.

70. Milicevic N, Duursma A, Ten Asbroek A, Felder-Schmittbuhl MP, Bergen AA. Does the circadian clock make RPE-mediated ion transport "tick" via SLC12A2 (NKCC1)? Chronobiol Int. 2019;36:1592-1598.

71. Milicevic N, ten Brink JB, ten Asbroek A, Bergen AA, Felder-Schmittbuhl MP. The circadian clock regulates RPEmediated lactate transport via SLC16A1 (MCT1). Exp Eye Res. 2020;190:107861.

72. Ikarashi R, Akechi H, Kanda Y, et al. Regulation of molecular clock oscillations and phagocytic activity via muscarinic $\mathrm{Ca}(2+)$ signaling in human retinal pigment epithelial cells. Sci Rep. 2017;7:44175.

73. Morioka E, Kanda Y, Koizumi H, Miyamoto T, Ikeda M. Histamine regulates molecular clock oscillations in human retinal pigment epithelial cells via H1 receptors. Front Endocrinol. 2018;9:108.

74. Johansson JK, Karema-Jokinen VI, Hakanen S, et al. Sodium channels enable fast electrical signaling and regulate phagocytosis in the retinal pigment epithelium. BMC Biol. 2019;17(1):63. https:// doi.org/10.1186/s12915-019-0681-1

75. Nandrot EF, Anand M, Almeida D, Atabai K, Sheppard D, Finnemann SC. Essential role for MFG-E8 as ligand for alphavbeta5 integrin in diurnal retinal phagocytosis. Proc Natl Acad Sci USA. 2007;104:12005-12010.

76. Tang Y, Lu Q, Wei Y, et al. Mertk deficiency alters expression of microRNAs in the retinal pigment epithelium cells. Metab Brain Dis. 2015;30(4):943-950. https://doi.org/10.1007/s1101 1-015-9653-5

\section{SUPPORTING INFORMATION}

Additional Supporting Information may be found online in the Supporting Information section.

How to cite this article: Milićević N, Ait-Hmyed Hakkari O, Bagchi U, et al. Core circadian clock genes Perl and Per2 regulate the rhythm in photoreceptor outer segment phagocytosis. The FASEB Journal. 2021;35:e21722. https://doi. org/10.1096/fj.202100293RR 